\title{
New regimen for treatment of irritable bowel syndrome with emphasis on Sulpride as the sole maintenance therapy
}

\author{
Kamel El-Reshaid *, Shaikha Al-Bader ** \\ *Department of Medicine, Faculty of Medicine, Kuwait University, P O Box 24923, 13110 Safat, Kuwait \\ ** Department of Medicine, Nephrology Unit, Amiri hospital, Ministry of health, Kuwait
}

\begin{abstract}
The efficiency and safety of Sulpirid (50 mg twice/daily) was assessed in 563 adult patients with 6 groups of patients with irritable bowel syndrome (IBS) who had failed dietary therapy. The groups included; patients without previous treatment (n: 137), patients who had received a muscarinic antagonists (n: 65), an anticholinergic/benzodiazepine combination (n: 187), a tricyclic antidepressants (n: 62), a selective serotonin reuptake inhibitors (SSRIs) (n: 48) and an antiflatulent (n: 64). Patients were assessed for 6 weeks. Sulpirid was effective and safe in safe in relieving the abdominalgia, anxiety, depression and bowel function. The overall success of Sulpride in treatment of IBS was $84 \%$. Most patients who had failed muscarinic antagonists, antiflatulent and tricyclic antidepressants had > 95\% improvement with Sulpride. The success was $88 \%$ in those who did not receive prior therapy while it was just $77 \%$ and $72 \%$ in those who had failed SSRIs and anticholinergic/benzodiazepine combination. In treatment-failures, a further $9.8 \%$ improvement was achieved with addition of a SSRI (Escitalopram) and an extra 3.4\% with subsequent increase in Sulpride dose to $100 \mathrm{mg} X 2$ limiting failures to only 2.3\%. Tolerance of treatment was good and side-effects developed in $11 \%$ patients. In conclusion: Sulpride is an effective and safe drug in IBS.
\end{abstract}

Keywords: Antidepressants, anxiolytics, irritable bowel syndrome, treatment, Sulpride

Article Info: Received 12 July 2019; Review Completed 19 August 2019; $\quad$ Accepted 24 August 2019; Available online 15 Sep 2019

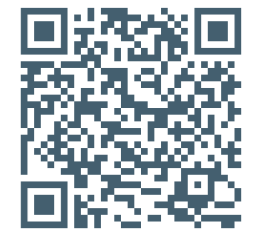

\section{Cite this article as:}

El-Reshaid K, Al-Bader S, New regimen for treatment of irritable bowel syndrome with emphasis on Sulpride as the sole maintenance therapy, Journal of Drug Delivery and Therapeutics. 2019; 9(5):154-157

http://dx.doi.org/10.22270/jddt.v9i5.3424

Dr. Kamel El-Reshaid, Professor, Dept. of Medicine, Faculty of Medicine, Kuwait University, P O Box 24923, 13110 Safat, Kuwait

\section{INTRODUCTION}

Irritable bowel syndrome (IBS) is a chronic alteration of colon function. Invasive gastrointestinal (GI) diagnostics are often unrevealing and hence its etiology has been considered a functional one [1]. According to its main presentation, it has been classified into diarrhea-predominant, constipationpredominant, and enterospasmodic disorders [2]. IBS is a common disorder affecting 10 to $15 \%$ of people in the developed world [3]. The aggregate cost of irritable bowel syndrome in the United States has been estimated at \$1.7-10 billion in direct medical costs, with an additional $\$ 20$ billion in indirect costs, for a total of $\$ 21.7-30$ billion [4]. The disorder is usually associated with anxiety, depression and mood disorder. Hence, low dose antidepressant drugs with or without antispasmodics has been used for its treatment [5]. Nortriptyline (Pamelor), a tricyclic antidepressant (TCA) which inhibits the gut nerve-activity, has been used for its enterospastic and diarrheal disorders. On the other side; a selective serotonin reuptake inhibitors (SSRIs) like Zoloft has been used to speed the gut in constipated subjects.
Moreover, direct antispamsmodics as well as antidiarrheal agents (Lopermide) and laxatives were common additives as well as benzodiazepine for anxiety with risk of addiction. In search for an acceptable treatment for IBS; we elected to evaluate the role of control of anxiety rather than depression in management of IBS. Hence, we conducted this study to evaluate the safety and efficacy of low dose of Sulpride in management of this disorder.

\section{PATIENTS AND METHODS:}

The study started from 1st of January 2014 till 31st June 2019. It included all patients who presented with IBS to the Al-Amiri nephrology center. The latter was established at Al-Amiri hospital in 1976 in the center of Kuwait city. It is the referral center for all patients with kidney diseases in the capital area of Kuwait. It has adequate diagnostic and therapeutic facilities to care for both in- and out-patients with renal diseases and all their medical problems. Moreover, it acted also as a tertiary kidney center for all Kuwait. 


\section{Inclusion criteria for IBS patients:}

Patients were included, in the study, if they fulfilled Rome IV criteria which include recurrent abdominal pain, on average, at least 1 day/week in the last 3 months, associated with defecation or associated with change in the frequency of defecation or appearance of stool [6].

\section{Exclusion criteria:}

1- Patients older than 50 years at start of symptoms or less than 14 years.

2- Those with nocturnal pains and weight loss.

3- Patients with GI reflux disease, peptic disease, Helicobacter infestation, coeliac disease (tested by both serological markers and biopsy of second part of duodenum), and inflammatory bowel disease. Moreover, patients with gall stones, gynecological disorders, autoimmune diseases and endocrine abnormalities. Hence all patients had normal: full blood testing, liver function tests, ESR, urine routine and microscopy, stool analysis, ultrasound of the abdomen and pelvis, upper and lower gastrointestinal endoscopy. TSH and Free T4 were done in all patients and tests for other endocrine glands as well as and autoimmune system when indicated.

4- Patients with creatinine clearance $<60 \mathrm{ml} /$ minute.

\section{Study design:}

Patients were included in the study if they did not receive prior treatment for IBS as well as those who had had failed previous drug-therapy. All patients had instructions regarding dietary measures that included increasing soluble fiber intake, gluten-free diet and avoidance of fermentable sugars for 6 weeks. Patients who did not improve or had failed other treatments were included in the study. Initially, all patients were treated, exclusively, with Sulpride $50 \mathrm{mg}$ $\mathrm{X} 2$ for 6 weeks. Failures were further retested after addition of Escitalopram up to $20 \mathrm{mg}$ at night to Sulpride $50 \mathrm{mg} \mathrm{X2}$ for another 6 weeks. Furthermore, subsequent failures were retested after increasing the dose of Sulpride dose to $100 \mathrm{mg}$ twice/daily in addition to Escitalopram.

\section{Statistical analysis:}

Since the age and duration of IBS prior to treatment were not normally distributed: (a) the median and (interquartile range) were used to express the groups and (b) KruskalWallies test was used to compare the difference between groups.

\section{RESULTS}

Over the past 4 and $1 / 2$ years, a total of 2371 patients were screened. Symptoms of significant IBS were detected in 577 patients (24\%). Fourteen patients lost follow up. The demographical data on the remaining 563 patients are summarized in (Table 1). All patients were adults with a median age of 32(11) and youngest was 18 and eldest was 46 years. Gender distribution was (Female/Male: 1.9 ). The median of duration of IBS prior to the study was 6(4) years and shortest was 2 and longest was 18 years.

\section{Study population:}

A 137 patients did not receive prior treatment for IBS while others had treatment-failure with; Mebevirine $\mathrm{HCl}$ (Duspatalin) as a muscarinic antagonists (n: 65), Chlordiazepoxide/clidinium bromide (Librax) as an anticholinergic/benzodiazepine combination (n: 187), Nortriptyline (Pamelor) as a TCA (n: 62), Sertraline (Zoloft) as a SRRI (n: 48) and Simithicone as an antiflatulent (n: 64). There was no statistical difference between the 6 groups with regards age and duration of IBS before entering the study.

\section{Efficacy of 6 weeks of Sulpride:}

The overall success of Sulpride in treatment of IBS was $84 \%$. Most patients who had failed muscarinic antagonists, antiflatulents and TCAs had improvement with Sulpride (> $95 \%)$. The success was also acceptable in those who did not receive prior therapy (88\%). However, the success rate was just $77 \%$ and $72 \%$ in those who had failed SSRI and anticholinergic/benzodiazepine combinations.

\section{Management of the initial non-responders:}

An additional 9.8\% improvement was achieved with additional of Escitalopram and further $3.4 \%$ with increasing Sulpride dose to $100 \mathrm{mg} \mathrm{X} 2$ leaving only $2.3 \%$ treatment failure.

\section{Treatment side-effects:}

Sulpride produced gynecomastia in 2 males and galactorrhea with amenorrhea in 8 conception-seeking females. It was entered as a treatment failure and the drug was discontinued. The extrapyramidal (Parkinsonian tremors) and anticholinergic side-effects were rarely seen at our adult population. Sedation limited increment of the dose of Escitalopram to $>10 \mathrm{mg}$ daily in 6 patients.

\section{Final treatment failures:}

Ten patients could not tolerate Sulpride therapy for sideeffects and 3 were true treatment failure.

\section{DISCUSSION}

The pathophysiology of IBS is uncertain. Theories include genetic mutations, abnormal GI motility, enhanced gut pain sensation (visceral hypersensitivity, bacterial flora overgrowth and psychological changes [7]. One theory concerning the pathophysiology of IBS involves the neurotransmission between the central nervous system (CNS) and the intestines. Numerous structures in the CNS connect to the gut through serotonergic nerves that help regulate its motility, sensation, and secretion. In patients with IBS, an imbalance in the function of serotonin leads to the deregulation of intestinal motility. Based on this serotonin imbalance theory, various treatment approaches have been suggested [8]. The most widely used antidepressants in IBS are TCAs and SSRIs, as they reduce pain and improve global IBS symptoms. Their analgesic and anxiolytic effect is thought to improve GI motility and function. However, in a recent meta-analysis of multiple studies, nearly half of patients were refractory to both treatments $[9,10]$. Local anticholinergic-antispasmodics such as Mebevirine, hyoscyamine, dicyclomine and belladonna have been utilized, for short term, relief of abdominal pain. However, common side-effects viz. dry mouth, dizziness, blurry vision, and urinary retention limit their long-term use especially in the elderly [11]. Moreover, major health concerns faced multiple drugs viz. (a) Alosetron, a 5- $\mathrm{HT}_{3}$ receptor antagonist used for treatment of IBS-D due to ischemic colitis (b) Tegaserod, a 5-HT 4 receptor agonist, used for treatment of IBS-C due to increased risk of heart attack and stroke (c) Lubiprostone, a chloride channel activator for the management of IBS-C due to pregnancy teratogenicity (d) linaclotide, a guanylate cyclase (GC-C) agonist and acts locally in the intestine due to concerns in pediatric patients and deaths in young juvenile mice and (e) Loperamide, a widely available OTC product, has shown to reduce GI transit time and improve diarrhea and urgency. 
However, it did not improve abdominal pain and global IBS symptoms [11, 12]. Dietary modification included; (a) exclusion of beans, alcohol, caffeine, and fatty meals, and gas-producing foods such as broccoli, legumes, cabbage, and avocado in diet and increase intake of dietary fiber ispaghula/psyllium (e.g. Metamucil) in constipated patients [13], (b) probiotics, containing Bifidobacterium, to prevent overgrowth of pathogenic GI bacteria in and reduce its triggering local inflammation [14], (c) Rifaximin, a locallyacting antibiotic used for traveler's diarrhea and hepatic encephalopathy since bacterial resistance and side effects were a major concern [15], and carminatives (Simithicone) as anti-foaming agent that decrease the surface tension of gas bubbles, causing them to combine into larger bubbles in the gut [16].

In our study, we elected to use a systemic a non-addicting anxiolytic agent since patients with IBS have multiple bodily symptoms (somatization) i.e. not a simple GI disorder [17]. Hence, we elected to use Sulpride. The drug is an atypical antipsychotic medication of the benzamide class. At highdoses, it is being used for treatment of psychosis associated with schizophrenia, major depressive disorders and panic attacks. However, in low-dosage it is an excellent anxiolytic agent. Contrary to benzodiazipines it is not associated with dependence, tolerance, hypoventilation and sleepiness [18]. It is a selective antagonist at dopamine D2, D3 and 5-HT1A receptors. Antagonism at 5-HT1A dominates in doses exceeding $600 \mathrm{mg}$ daily. In low doses, 50-20 mg daily, its prominent feature is antagonism of presynaptic inhibitory dopamine and serotonin receptor, accounting for some antidepressant activity as well as stimulatory effect [19]. Moreover, its beneficial effects include; activation of the endogenous gamma-hydroxbutyrate receptor in vivo at therapeutic concentrations, their upregulation in animal studies and activation of their DNA demethylation in the brain [19-21]. The drug was well tolerated and produced few side-effects (10\%). Hyperprolactinemia, leading to gynecomastia in males and galactorrhea with amenorrhea in conception-seeking females limited its use. Moreover, its extrapyramidal (Parkinsonian tremors) and anticholinergic side-effects were rarely seen at our adult population [18]

To improve the rate of success we elected first to add Escitalopram. The latter is a SSRI with limited anticholinergic side-effects yet with potent anti-somatoform effect [22]. Finally, patients who did not respond to Sulpride- Escitalopram combination had to be treated with higher dosage of Sulpride and it further improved the success rate. In our study, we elected to avoid highmaintenance dosage of Sulpride to avoid its short and longterm side-effects. In conclusion; Sulpride is a safe and efficacious agent in management of IBS.

\section{REFERENCES:}

1- Fass R, Longstreth GF, Pimentel M, Fullerton S, Russak SM, Chiou CF, et al. Evidence- and consensus-based practice guidelines for the diagnosis of irritable bowel syndrome. Arch Intern Med 2001;161: 2081-2088.

2- Diagnosing the Patient with Abdominal Pain and Altered Bowel Habits: Is It Irritable Bowel Syndrome?. HOLTEN KB, BANKSTON L, Am Fam Physician 2003; 67: 2157-2162.

3- Maxion-Bergemann S, Thielecke F, Abel F, Bergemann R. "Costs of irritable bowel syndrome in the UK and US". PharmacoEconomics 2006; 24: 21-37.

4- Hulisz D. "The burden of illness of irritable bowel syndrome: current challenges and hope for the future". Journal of Managed Care Pharmacy 2004; 10: 299-309.

5- Whitehead WE, Palsson O, Jones KR. "Systematic review of the comorbidity of irritable bowel syndrome with other disorders: what are the causes and implications?". Gastroenterology 2002; 122: 1140-1156.
6- Drossman DA. "Functional Gastrointestinal Disorders: History, Pathophysiology, Clinical Features and Rome IV". Gastroenterology 2016;150: 1262-1279.e2.

7- Yoon SJ, Grundmann 0, Koepp L, et al. Management of irritable bowel syndrome (IBS) in adults: conventional and complementary/alternative approaches. Alt Med Rev 2011; 16: 134-150.

8- Vahedi H, Ansari R, Mir-Nasseri MM, et al. Irritable bowel syndrome: a review article. Mid East J Digest Dis 2010; 2: 6677.

9- Ford AC, Quigley EMM, Lacy BE, et al. Effect of antidepressants and psychological therapies, including hypnotherapy, in irritable bowel syndrome: systematic review and metaanalysis. Am J Gastroenterol 2014;109:1350-1365.

10- Chang L, Lembo A, Sultan S. American Gastroenterological Association Institute technical review on the pharmacological management of irritable bowel syndrome. Gastroenterology 2014; 147: 1149-1172.

11- Saad RJ. Peripherally acting therapies for the treatment of irritable bowel syndrome. Gastroenterol Clin North Am 2011; 40: 163-182.

12- Ironwood and Forest announce FDA approval of Linzess (linaclotide) for the treatment of irritable bowel syndrome with constipation and chronic idiopathic constipation. Forest Laboratories, Inc. http://news.frx.com/pressrelease/corporate-news/ironwood-and-forest-announce-fdaapproval-linzesstm-linaclotide-treatme. Accessed September 23, 2012.

13- Eswaran S, Tack J, Chey WD. Food: the forgotten factor in the irritable bowel syndrome. Gastroenterol Clin North Am 2011; 40: 141-162.

14- Smith L. Irritable bowel syndrome. In: Richardson M, Chant C, Chessman $\mathrm{KH}$, et al, eds. Gastroenterology and Nutrition: Pharmacotherapy Self-Assessment Program. 7th ed. Lenexa, KS: American College of Clinical Pharmacy; 2012: 49-65.

15- Smith L. Irritable bowel syndrome. In: Richardson M, Chant C, Chessman $\mathrm{KH}$, et al, eds. Gastroenterology and Nutrition: Pharmacotherapy Self-Assessment Program. 7th ed. Lenexa, KS: American College of Clinical Pharmacy; 2012:49-65.

16- Bendezu RA, Barba E, Burri E, et al. Intestinal gas content and distribution in health and in patients with functional gut symptoms. Neurogastroenterol Motil 2015; 27:1249-1257.

17- Miller A R, North C S, Clouse R E. et al The association of irritable bowel syndrome and somatization disorder. Ann Clin Psychiatry 20011325-30

18- Joint Formulary Committee (2013). British National Formulary (BNF) $\left(65^{\text {th }}\right.$ ed). London, UK: Pharmaceutical Press. ISBN 978-0-85711-084-8.

19- Maitre M, Ratomponirina C, Gobaille S, Hodé Y, Hechler V. "Displacement of [3H] gamma-hydroxybutyrate binding by benzamide neuroleptics and prochlorperazine but not by other antipsychotics". Eur J Pharmacol 1994; 256: 211-214.

20- Ratomponirina C, Gobaille S, Hodé Y, Kemmel V, Maitre M. "Sulpiride, but not haloperidol, up-regulates gammahydroxybutyrate receptors in vivo and in cultured cells". Eur J Pharmacol 1998; 346: 331-337.

21- Dong, E; Nelson, M; Grayson, DR; Costa, E; Guidotti, A (August 2008). Clozapine and sulpride but not haloperidole or olanzapine activate brain DNA demethylation. Proceedings of the National Academy of Sciences of the United States of America 2008; 105: 13614-13619.

22- Aragona M, Bancheri L, Perinelli D. et al. Randomized doubleblind comparison of serotonergic (citalopram) versus noradrenergic (reboxetine) reuptake inhibitors in outpatients with somatoform, DSM-IV-TR pain disorder. Eur J Pain 2005; 9: 33-38. 
Table 1. Showing the results of Sulpride treatment in patients with IBS*

\begin{tabular}{|c|c|c|c|c|c|c|c|c|c|c|}
\hline Group & No. & $\begin{array}{l}\text { Age } \dagger \\
\text { (years) }\end{array}$ & $\begin{array}{l}\text { Sex } \\
\mathrm{M} / \mathrm{F}\end{array}$ & $\begin{array}{l}\text { Duration of } \dagger \\
\text { IBS }\end{array}$ & $\begin{array}{c}\text { Previous treatment } \\
\text { (>3 months) }\end{array}$ & $\begin{array}{r}\text { Sulpride } \\
\text { Improved }\end{array}$ & $\begin{array}{l}\mathrm{X} 2 \\
\text { No } \\
\text { change }\end{array}$ & $\begin{array}{c}(+) \\
\text { Cipralex } \\
\end{array}$ & $\begin{array}{c}\text { Further } \\
\text { management } \\
\text { Sulpride } 100 \mathrm{mg} \\
\text { X2 } \\
\end{array}$ & Failed \\
\hline 1 & 137 & $32(12)$ & $43 / 94$ & $6(4)$ & None & $121(88 \%)$ & 16 & 10 & 3 & 3 \\
\hline 2 & 65 & $32(12)$ & $23 / 42$ & $6(3)$ & Direct gut antispasmodics $* *$ & $63(97 \%)$ & 2 & 2 & 0 & 0 \\
\hline 3 & 187 & $32(13)$ & $57 / 130$ & $6(4)$ & $\begin{array}{c}\text { Anticholinergic }+ \text { benzodiazepine } \\
* * *\end{array}$ & 134 (72\%) & 53 & 35 & 12 & 6 \\
\hline 4 & 62 & $32(11)$ & $28 / 34$ & $6(5)$ & Tricyclic antidepressants $\square$ & $59(95 \%)$ & 3 & 3 & 0 & 0 \\
\hline 5 & 48 & $34(13)$ & $26 / 22$ & $6(4)$ & SSRI $\square$ & $37(77 \%)$ & 11 & 3 & 4 & 4 \\
\hline 6 & 64 & $32(11)$ & $18 / 46$ & $6(4)$ & Antiflatulents $\square \square \square$ & $62(97 \%)$ & 2 & 2 & 0 & 0 \\
\hline Total $(\%)$ & 563 & $32(11)$ & $195 / 368$ & $6(4)$ & & $476(84.5 \%)$ & $\begin{array}{c}87 \\
(15.5 \%) \\
\end{array}$ & $55(9.8 \%)$ & $19(3.4 \%)$ & $\begin{array}{c}13 \\
(2.3 \%) \\
\end{array}$ \\
\hline
\end{tabular}

* Sequential treatment: Sulpride $50 \mathrm{mg} \mathrm{X2}$ for 6 weeks then failures had Escitalopram for additional 6 weeks

then failures had increment of Sulpride dose to $100 \mathrm{mgX} 2$ for extra 6 weeks

$\dagger$ Age \& duration of IBS are expressed in median(IQR)

** Direct gut antispasmodics (muscarinic antagonist): Duspatalin

*** Anticholinergic+Benzodiazepine: Chlordiazepoxide/clidinium bromide (Librax)

$\square$ Tricyclic antidepressants: Nortrtriptyline (Pamelor)

$\square$ Selective serotonin reuptake inhibitors (SSRIs): Sertaline (Zoloft)

प्र Antiflatulents: Simithicone 